\title{
Peer-led team learning for introductory biology: relationships between peer-leader relatability, perceived role model status, and the potential influences of these variables on student learning gains
}

\author{
Christina I. Winterton ${ }^{1}$ (D), Ryan D. P. Dunk ${ }^{2}$ (I) and Jason R. Wiles ${ }^{1,2^{*}}$ (1)
}

\begin{abstract}
Student-instructor interactions have an influence on student achievement and perceptions of learning. In college and university settings, large introductory STEM courses are increasingly including Peer-Led Team Learning (PLTL), an evidence-based technique associated with improved student achievement, recruitment, and retention in STEM fields, especially for underserved populations. Within this technique, peer leaders hold a unique position in a student's education. Peer leaders have relevant experience in that they have had recent success in the courses in which they facilitate student learning, yet, compared to student-faculty or student-teaching assistant relationships, there is minimal imbalance of authority or power. Students might find their peer leaders to be more relatable than faculty or graduate teaching assistants, and may even consider them to be role models. We explored students' perceptions of peer leader relatability and role model status in relation to students' achievement and their perceived learning gains in the context of an introductory biology course with an associated PLTL program. The final course grades and self-assessed learning gains of PLTL students who felt they related to their peer leader were compared to those who did not. We also compared final course grades and self-assessed learning gains between PLTL students who viewed their peer leader as a role model versus those who did not. Self-reported learning gains were significantly higher for students who relate to their peer leader, as well as for students who viewed their peer leaders as a role model. There is some support that this trend is stronger for STEM majors versus those who are not enrolled in a STEM program, though the interaction is not significant. Significant differences in overall course grade were only observed between students who reported that they related to their peer leader versus those who did not relate to their peer leader.
\end{abstract}

Keywords: Peer-led team learning, Role models, STEM, Active learning, Student interactions, Higher education

\section{Introduction}

In the United States, the comparatively low number of completed degrees in the science, technology, engineering and mathematics (STEM) fields is of current concern. The National Science Board (National Science Board, 2016) has reported that compared to China, India, and the European Union, the U.S. holds a relatively low number of all science and

\footnotetext{
* Correspondence: jwiles01@syr.edu

'Department of Science Teaching, Syracuse University, Syracuse, NY, USA

${ }^{2}$ Department of Biology, Syracuse University, Syracuse, NY, USA
}

engineering degrees conferred globally, at only $9 \%$. Additionally, the NSB Science and Engineering Indicators (2018) shows that the United States is not meeting its goal of leading the way for advancements in science and related industries, and in fact has a lower level of basic STEM skills than many other countries. There is national recognition of an inadequate number of STEM graduates to fulfill the need for STEM careers. In 2018, the White House released a 5 year STEM strategy outlining the visions and goals for STEM education in the United States, particularly now that STEM employment 
opportunities are growing at a faster pace than non-STEM employment opportunities (http://www.whitehouse.gov). The low number of conferred degrees, alongside the lack of basic STEM skills, leaves many unfilled employment opportunities, which means that the United States is not producing the number of STEM graduates required for its desired workforce (Chen, 2013).

\section{Factors influencing student attrition}

Of key importance to efforts aimed at achieving more STEM degrees and a higher level of basic STEM skills is to keep students engaged and satisfied with their undergraduate coursework. Research shows students tend to find STEM courses competitive, unsupportive, and unwelcoming, and they perceive an uncomfortable distance between themselves and their professors (Seymour \& Hewitt, 1997). To keep students in STEM disciplines, classroom factors such as outdated and ineffective modes of teaching, an intimidating classroom climate, and a general lack of student nurturing need to be addressed (Finn \& Campisi, 2015; Seymour \& Hewitt, 1997). STEM attrition, defined as students "moving away from STEM fields by switching majors to non-STEM fields or leaving postsecondary education before earning a degree or certificate" (Chen, 2013, p. iii), is not merely a matter of poor course performance. It is, rather, a problem for both high performing and low performing students in STEM courses (Marra, Rodgers, Shen, \& Bogue, 2012; Seymour \& Hewitt, 1997). Hence, additional factors must be considered alongside possible solutions for students to feel more connected to the instructor and the course content.

While some factors contributing to attrition rates are more or less outside of institutional control (e.g. student finances, poor student-institution fit, and changing of career goals), Lau (2003) also identified institutional factors that could potentially be addressed by shifting from traditional, lecture-based methods to an active learning approach. Lau's first factor was that traditional learning environments are often not aligned with the educational needs of all students. Lau's second factor is coursework and course load expectations that are outside of many students' ability to manage effectively. Where active learning strategies may be most effective is in addressing the failure of institutions to adequately engage and motivate students, which has been attributed to a lack of appreciation for material presented in the classroom because it is not applied to real world situations (Lau, 2003). Lau proposed that a third factor contributing to attrition from STEM fields is the lack of appropriate role models or mentors in the academic environment. Peer Led Team Learning (PLTL) is an active learning strategy that has the capacity to address these concerns regarding inadequate learning environments and students' ability to manage coursework while simultaneously presenting students with a potential role model who may be more relatable than a faculty member. It is reasonable to expect that student-peer leader interactions may differ in their dynamics from student-faculty interactions in ways that could potentially influence student persistence in STEM majors.

\section{The impact of student perception in learning}

Micari and Pazos (2012) found that students who perceived positive relationships with faculty earned higher grades and had increased confidence in introductory chemistry courses. Their research identified faculty approachability, faculty respect for students, and students perceiving the faculty as a role model as the qualities defining a positive student-faculty relationship. Similarly, our study aims to measure potential benefits of Peer-Led Team Learning among students who view their peer leader as relatable, and, separately, as a role model. Peer leaders have been assumed to be role models in previous research (Johnson, Robbins, \& Loui, 2015; Wilson \& Varma-Nelson, 2016), and it reasonable to expect additional academic benefits for students who perceive their peer leaders as role models. In addition, we will explore how student-peer leader relationships may be associated with students' level of achievement and perceived learning gains in the context of a high-enrollment introductory biology course.

\section{Peer-led team learning and student-student interactions}

PLTL has been implemented in a diverse array of higher education settings where it has provided an opportunity for students to learn outside of traditional lecture halls with a group of 6-8 fellow students and a peer-leader who has previously been successful in the same course (Gosser et al., 1996). PLTL workshops commonly supplement larger introductory courses and have been successfully implemented in a wide variety of STEM fields such as biology, chemistry, computer science and mathematics (Eberlein et al., 2008; Quitadamo, Brahler, \& Crouch, 2009; Stewart-Gardiner, 2010). The success of the PLTL model has been credited to the student-tostudent interactions and an environment that promotes discussion, is non-judgemental, and may be less intimidating for many students (Finn \& Campisi, 2015; White, Rowland, \& Pesis-Katz, 2012). Additionally, these interactions often take place between the students and a peer leader without the direct oversight of someone with authority to assign grades in the course, such as a professor or a teaching assistant.

PLTL relies on the attendance and active participation of students in weekly workshops to complete prescribed problem sets and construct original responses through discussion and collaboration. The discussion is facilitated 
by the peer leader, a student who has recently succeeded in the course and trained in group leadership by a learning specialist (Gosser et al., 2001; Gosser Jr. \& Roth, 1998; Tien, Roth, \& Kampmeier, 2004). The main role of the peer leader is not to provide answers to the problems or to teach students directly, but rather, to engage the group in problem-solving activities, facilitate student conversations of scientific concepts and ideas, and encourage students to develop their own conceptual understanding of scientific topics (Eberlein et al., 2008; Gosser et al., 2001). A notable difference between a peer leader and a typical professor of a large course is that peer leaders have the ability to relate to and support their students from a perspective of recent personal experience and success as students in the same course (Finn \& Campisi, 2015; White et al., 2012). Gosser et al. (2001) asserts that, while peer leaders are not to be considered experts in the field, their status as students who recently and successfully completed the course positions them well as facilitators in a nonthreatening setting.

If students were to view their peer leader as a role model this would help to address the third factor of attrition identified by Lau (2003). The unique relationship between peer leaders and students may bridge the gaps associated with faculty instructors' perceived relatability or status as a viable role model. These characteristics may enhance the already documented benefits of faculty investments in student learning and active learning techniques such as increased persistence, retention and course satisfaction (Braxton, Milem, \& Sullivan, 2000), as well as increase student enthusiasm for learning (Woodward, Gosser, \& Weiner, 1993). Collaboration has been shown to enhance learning outcomes such as academic achievement, student attitudes, and student retention (Prince, 2004). In general, as students learn more they will feel more satisfied with the course, tend to enroll in more courses in the discipline, and persist to graduation (Zerger, Clark-Unite, \& Smith, 2006). PLTL has already been shown to improve student attitudes towards the subject under study, as well as increase exam scores, quiz grades, and final course averages (Eberlein et al., 2008; Finn \& Campisi, 2015; Gosser et al., 1996; Peteroy-Kelly, 2009; Snyder, Carter, \& Wiles, 2015; Snyder, Sloane, Dunk, \& Wiles, 2016; Wilson \& VarmaNelson, 2016). We therefore also expected that the interactions between peer leader and student during PLTL sessions may influence students' self-assessed learning gains and final course grade in our course.

\section{Peer leaders as role models}

Previous literature has suggested that peer leaders serve as more than just facilitators during PLTL sessions, asserting that they may also serve as role models to the students in the PLTL group (Wilson \& Varma-Nelson,
2016). The eligibility criteria for service as a peer leader include having earned a high grade in the given course as well as receiving group leadership training with a learning specialist, and these criteria are communicated to the students they will lead. It is therefore possible that students might naturally view peer leaders as competent and exemplars of behavior associated with success in STEM. Additionally, students are likely to find similarities between themselves and the peer leader that can help to establish relatability. Recent completion of the same course may seem trivial, but previous research has found shared attributes such as attending the same university, enrolling in the same major, having the same career goals, or having the same desire for academic success can be enough to establish relatability (Lockwood \& Kunda, 1997). Even aspects of a shared college-life experience outside of academics, such as familiarity with local student spaces and the campus social scene may generate feelings of similarity or relatedness (Brown, Novick, Lord, \& Richards, 1992). Given all of this, peer leaders may be expected to meet the two characteristics identified by Marx and Ko (2012) as essential to role model status that will enhance the behavior of others: similarities and competency.

\section{Scope of study}

The current study aims to determine the students' perception of their peer leader as 1) relatable and 2) a role model, and to study the impact these perceptions have on students' self-assessed learning gains as well as final course grades. Based on prior research described above, we expected to find a high percentage of students who related to their peer leader, and a substantial number of students who considered their peer leader to be a role model. We further expected that these positive relationships would result in higher perceived learning gains and final course grades when compared to PLTL students who did not view their peer leader as either relatable or a role model. Our findings will shed light on how interactions between peer leaders and students enhance student success and provide further insight into the benefits of the PLTL model.

We used the following tests to explore whether students viewing their peer leader as relatable, and separately, as a role model may have an influence on students' self-assessed learning gains and final course grades:

i. The effect of students' perceptions of their peer leader as relatable and STEM major status on their self-assessed learning gains, determined by two-way ANOVA

ii. The effect of students' perceptions of their peer leader as a role model and STEM major status on 
their self-assessed learning gains, determined by two-way ANOVA

iii. The effect of students' perceptions of their peer leader as relatable on final course grade, determined by Chi square analysis

iv. The effect of students' perception of their peer leader as a role model on final course grade, determined by Chi square analysis

\section{Methods}

\section{Study population and conceptual assumptions}

The PLTL students $(n=204)$ and the peer leaders $(n=$ 43) in this study were all undergraduate students at a large, private research university in the northeastern United States. Students enrolled in the PLTL sessions were concurrently enrolled in BIO 121, the first semester course of an introductory biology sequence with a laboratory component for majors and non-majors. The introductory biology course is required for biology and other life science majors as well as many related STEM programs and pre-health professions programs. It also serves as a general education science course for nonSTEM majors.

The study population consisted of students currently enrolled in BIO 121 and actively attending PLTL sessions $(n=204)$. Analyses of student data were limited to data from those participants who fully completed the Student Assessment of their Learning Gains (SALG) survey (Seymour, Wiese, Hunter, \& Daffinrud, 2000). The SALG instrument was chosen as a research tool for this study because it is completely modifiable to instructor needs, can be used as a baseline assessment or summative assessment, and can gauge self-assessed student learning gains in categories such as class impact on attitude, increase in skills, and integration of learning (Scholl \& Olsen, 2014). Although self-report measures have raised concerns due to possible measurement errors, the SALG has been the prevailing choice of PLTL research on student's perceived learning gains (Wilson \& Varma-Nelson, 2016).

The PLTL program associated with BIO 121 has been the subject of several published studies which describe the program itself and how it is structured (for details, see Snyder \& Wiles, 2015; Snyder et al., 2015; and Snyder et al., 2016. PLTL problem sets employed were those published by The Center for Peer-led Team Learning (https:// sites.google.com/site/quickpltl/workshop-materials) and the Peer-Led Team Learning International Society (https://pltlis.org/resources/modules/introductory-biology/). The peer leaders who participated in this study have met the criteria for recruitment as peer leaders specified in the PLTL literature, having recently completed the introductory biology course with a final course grade of A or B. All students who had earned a qualifying grade in the immediately preceding year's course were invited to participate along with others who had completed the course prior to this and who had expressed interest in becoming peer leaders. Potential participants from this pool self-selected for service according to their schedule availability and other aspects of time commitment and were individually approved by the learning specialist. All peer leaders led one 55-min PLTL session per week of the semester and were concurrently enrolled in a PLTL Leadership Training course. The course in group leadership was instructed by the learning specialist and addressed various pedagogical approaches and techniques for facilitating student teams toward collaborative construction of responses to instructor-prescribed problem sets.

\section{Surveys}

The PLTL students in this study were contacted by the coordinator of the introductory biology course and offered a small extra credit incentive to complete two online surveys. The first survey was a qualitative questionnaire which contained the questions "Do you relate to your peer leader?" and "Do you consider your peer leader to be a role model in any way?". The second questionnaire was a modified version of the Student Assessment of their Learning Gains (SALG) survey containing 25 Likert-scale questions. The SALG instrument was determined to be best suited for this study based on research goals, theory base, target audience, time constraints, and flexibility (Seymour et al., 2000). The SALG survey responses were used in combination with formal course assessments to determine student learning outcomes and help identify which aspects of PLTL and student-peer leader interactions have benefited students the most. The SALG survey is a self-assessment of learning gains that allowed us to gauge how students perceived the educational value of PLTL in addition to the students' final course grades as a more direct measure of educational achievement. The SALG survey contains questions relating to areas outside of content mastery, such as enthusiasm for the material, integration of knowledge, and likelihood to pursue the subject after the completion of the current course.

\section{Data analyses}

Statistical analyses of the quantitative data collected from administering the SALG instrument to students were performed with SPSS version 24 and R 3.4.1. The summation of all SALG responses was used for analyses. Cronbach's alpha, a measure of internal consistency, was determined for students' SALG scores to verify that the SALG instrument was able to be used as a single measure of learning gains. Cronbach's alpha was found to be 0.98 , which is considered excellent; indicating that using 
the sum of SALG answers is a defensible measure of students' perceived learning gains.

A two-way ANOVA was performed to determine the effect of viewing their peer leaders as relatable on the students' SALG scores; STEM major status was included as a second explanatory variable as well as the interaction between relatability and major. Similarly, a twoway ANOVA was performed to determine the effect of students viewing the peer leader as a role model on the students' SALG scores; STEM major status and interaction between role model status and major were again included as additional explanatory variables. ANOVA assumptions were tested and met (Levene tests and Shapiro-Wilk tests all insignificant).

A Pearson's chi square $2 \times 2$ test of independence was used to analyze the association between final course grades and answer on the "relate" and "role model" questions, with final course grade of students finishing the course with an A or B compared to students in the $\mathrm{C}, \mathrm{D}$, and $\mathrm{F}$ grade ranges. For the purposes of this study, a final course grade of A or B is considered to be successful completion as this is the commonly accepted grade requirement for students to be eligible to serve as PLTL leaders, and because a grade of A or B in this course is required as a prerequisite for several majors and potential subsequent courses. A significance level of $\alpha \leq 0.05$ was used for all calculations.

\section{Results}

Students who reported relating to their peer leader had greater self-assessed learning gains and final course grades than those who do not relate to their peer leaders Students who related to their peer leader had significantly higher SALG scores than students who did not,
Table 1 Two-Way ANOVA Testing Peer Leader Relatability and Student Major on Student Perceived Learning Gains

\begin{tabular}{llllll}
\hline Source & SS & Df & Mean-square & $F$ & $P$ \\
\hline STEM Major & 3 & 1 & 3 & .01 & .943 \\
Relatability & 2932 & 1 & 2932 & 5.18 & $.025^{*}$ \\
STEM Major: Relatability & 47 & 1 & 47 & .08 & .775 \\
Error & 63,447 & 112 & 566.49 & & \\
\hline
\end{tabular}

Note. Significant at the $p<0.05$ level

when controlling for STEM major status $(\mathrm{df}=1,112$; $\mathrm{F}=5.145 ; p=.0248$; Fig. 1B). STEM major status did not have a significant effect on SALG scores $(\mathrm{df}=1,112$; $\mathrm{F}=.01 ; p=.943)$, and there was no significant interaction $(\mathrm{df}=1,112 ; \mathrm{F}=.08 ; p=.775)$. The full two-way ANOVA results for "relate" can be seen in Table 1 .

Students who relate to their peer leader also earned a final grade of A or B in the associated introductory biology course significantly more often than their fellow PLTL students who indicated they did not relate to their peer leader (Pearson's chi square: $\mathrm{X}^{2}=4.021, \mathrm{df}=1$, $p=.045$; Fig. 1A), and these students and their final course grades can be seen in Table 2 .

\section{Students who considered their peer leader to be a role model had greater self-assessed learning gains than those who did not consider their peer leader to be a role model}

The students were asked to respond "yes" or "no" to the question "Do you consider your peer leader a role model in any way?". Students who considered their peer leader a role model had significantly higher SALG scores than students who did not, when controlling for STEM major status $(\mathrm{df}=1,111 ; \mathrm{F}=4.13 ; p=.044 ;$ Fig. $2 \mathrm{~A})$. The full

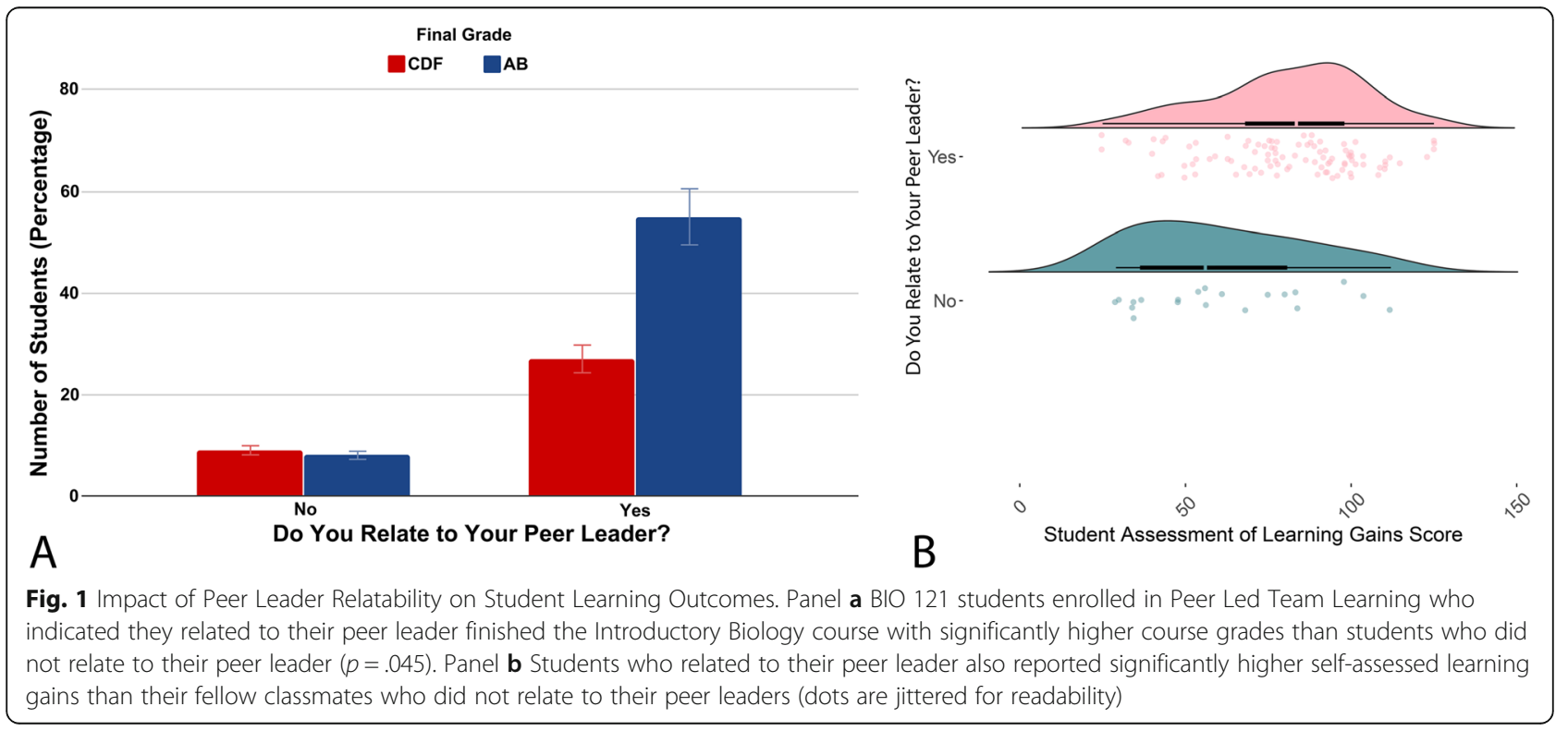


Table 2 Frequencies of students by final course grade and whether students relate to their peer leader

\begin{tabular}{lcc}
\hline & \multicolumn{1}{c}{ BIO 121 Grade } & \\
\cline { 2 - 3 } & $\underline{\mathrm{AB}}$ & $\underline{\mathrm{CDF}}$ \\
\hline Not Relatable & 17 & 19 \\
Relatable & 112 & 56
\end{tabular}

two-way ANOVA results for "role model" can be seen in Table 3.

STEM major status had no effect on SALG scores $(\mathrm{df}=1,111 ; \mathrm{F}=1.05 ; p=.308)$, but there was an interaction (Table 3), though not statistically significant, such that the impact of role model perception tended to be more important for STEM majors than non-STEM majors $(\mathrm{df}=1,111 ; \mathrm{F}=2.88 ; p=.092$; Fig. 3$)$.

No significant differences in final grades were found between PLTL students who viewed their peer leader as a role model and those who did not (Table $4, \mathrm{X}^{2}=1.301$, $\mathrm{df}=1, p=.254$; Fig. 2B).

\section{Discussion}

We chose to explore perceived peer-leader relatability and role model status as these factors are underresearched aspects of the Peer Led Team Learning model in general, and more specifically pertaining to the environment of the PLTL sessions and the role of peer leaders. Finding the peer leader relatable may help to mitigate feelings of intimidation in introductory STEM environments, promote learning, and lay the groundwork for viewing the peer leader as a role model. In addition to potentially increasing achievement and decreasing course attrition, providing students with a near-
Table 3 Two-Way ANOVA testing peer leader role model status and student major on student perceived learning gains

\begin{tabular}{llllll}
\hline Source & SS & Df & Mean-square & $F$ & $P$ \\
\hline STEM Major & 539 & 1 & 539 & 1.05 & .308 \\
Role Model & 2125 & 1 & 2125 & 4.13 & $.044^{*}$ \\
STEM Major: Role Model & 1482 & 1 & 1482 & 2.88 & .092 \\
Error & 57,051 & 111 & 513.97 & & \\
\hline
\end{tabular}

Note. Significant at the $p<0.05$ level

peer role model has been found to increase motivation, recruitment, and retention in STEM fields (Drury, Siy, \& Cheryan, 2011). Further, PLTL addresses another attrition factor identified by Lau (2003) by providing students with an environment conducive to learning, evinced in our population by the high self-assessment of learning gains and final course grades. Viewing the peer leader as relatable and, separately, considering the peer leader to be a role model, was associated with higher student assessment of students' learning gains from PLTL sessions (Figs. 1 \& 2). This is important if institutions are interested in decreasing attrition rates, as students who feel that they are indeed learning and who view themselves as successful are more likely to remain in a course and persist in the discipline through graduation (Zerger et al., 2006).

In addition to perceiving higher learning gains, students who identified their peer leader as relatable earned higher final course grades (Fig. 1). This makes sense and is encouraging in the light of prior research, as selfassessed proficiency and feelings of learning have been shown to be positive predictors of academic achievement (Cassidy \& Eachus, 2000). Further, it is likely that this

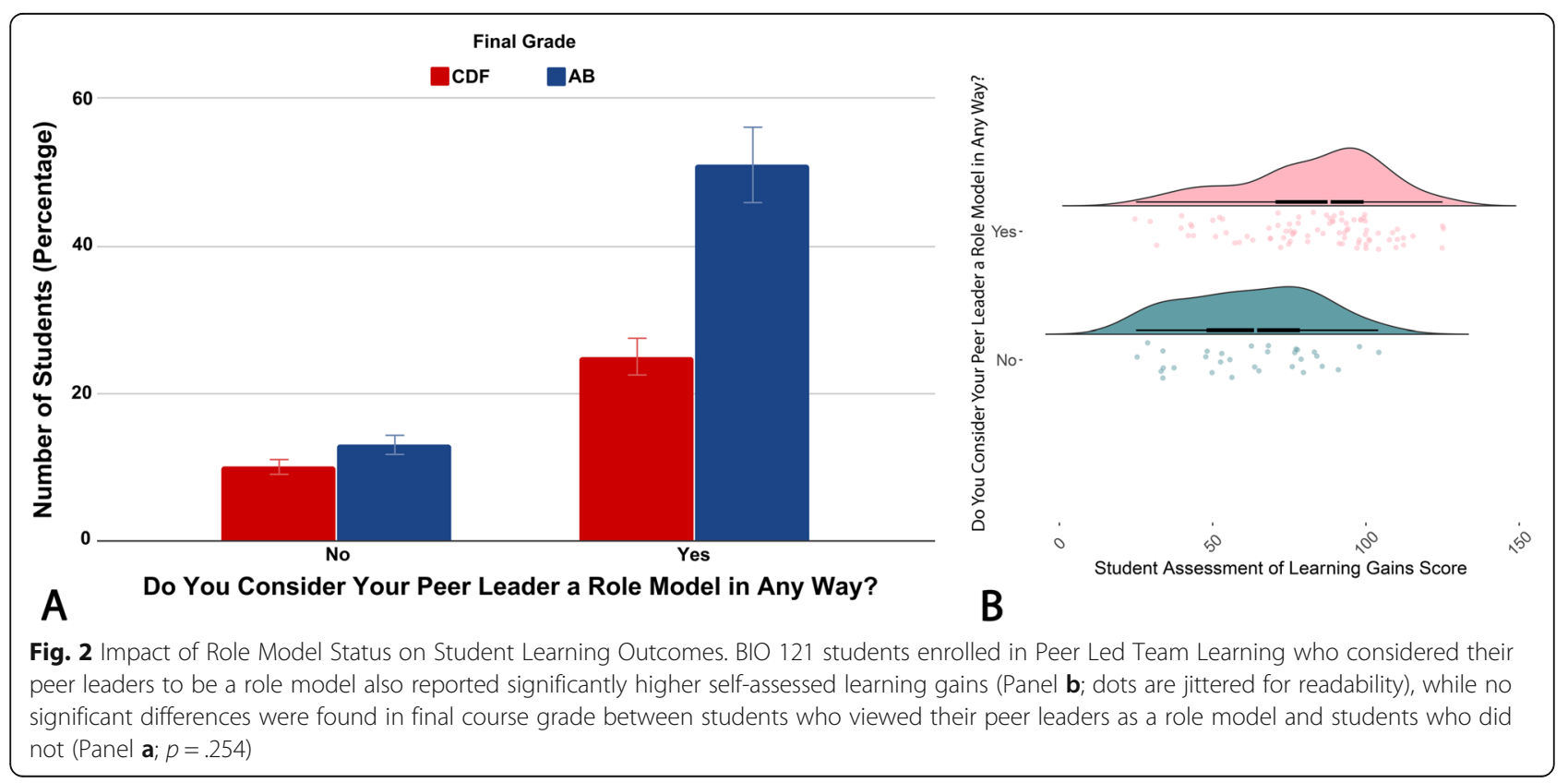




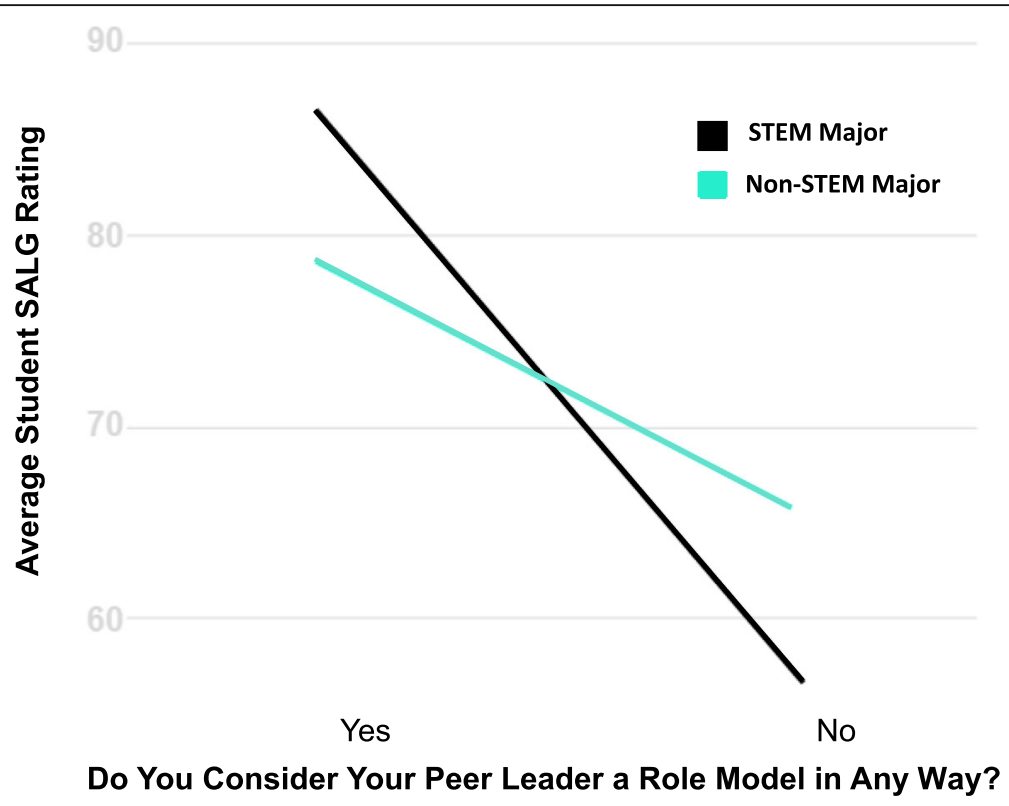

Fig. 3 Interaction of student major and peer leader role model status on student perceived learning gains. This figure illustrates the trend that a peer leader who is considered to be a role model by their students has a stronger yet statistically insignificant $(p=.092)$ association with the student perceived learning gains of STEM majors as compared to non-STEM majors

self-recognition of learning has some association with student affect measures such as self-efficacy, which has long been known to have an impact on achievement and student persistence (Multon, Brown, \& Lent, 1991).

We have shown that viewing the peer leader as a role model is associated with an increase in student perceived learning gains (Fig. 2). While the interaction is not significant (Fig. 3), there is some support that this trend is stronger for STEM majors versus those who are not enrolled in a STEM program (two-way ANOVA: $\mathrm{F}=2.88$; $\mathrm{df}=1,111 ; p=0.092$ ). It would be valuable to explore these relationships further in other populations and with qualitative data, as it indicates that viewing the peer leader as a role model may provide additional benefits in perceived learning gains among STEM majors. Previous research on role models other than PLTL leaders shows that relatable, positive STEM role models have had a positive effect on motivation, recruitment, and increases retention in the field (Drury et al., 2011).

The findings of this study are very important for improving the future implementation of PLTL at our institution. The

Table 4 Student frequencies by final course grade and student consideration of peer leaders as role models

\begin{tabular}{lcl}
\hline & BIO 121 Grade & \\
\cline { 2 - 3 } & $\mathrm{AB}$ & CDF \\
\hline Not a Role Model & 27 & 21 \\
Role Model & 102 & 51 \\
\hline
\end{tabular}

interactions between students and peer leaders are of interest because they will not only contribute to a conducive learning atmosphere and success in the course, but may also contribute to the larger problem of student attrition. Interactions with instructors have been found to be influential in students' decisions to exit from STEM programs (Pascarella, 2006), with students specifically identifying factors such as the lack of a nurturing environment and their perception that professors are only secondarily focused on education in deference to their primary focus on research (Braxton et al., 2000). Comparing the interactions of student-peer leader relationships to those of student-faculty relationships may identify important modifications instructors can make throughout their course to improve the student-instructor dynamic, perceptions of learning and final course grades, and increase student retention.

\section{Conclusion}

Peer leader relatability and role model status are critical components of the student-peer leader relationship, and it is critical to analyze and determine which, and to what extent, certain aspects of these interactions may contribute to students' learning gains and overall course achievement.

A majority of the students in our Peer-Led Team Learning program viewed their peer leader as relatable and, separately, considered their peer leader as a role model in some way. This further supports the assertion that relatability is important in a leader's function as a potential role model and validates the casual comparison of peer leaders to role models in prior PLTL literature. 
In addition to providing students an easily accessible role model in the STEM fields, students who consider their peer leader to be a role model perceived significantly higher self-assessed learning gains than those who do not. Students who report relating to their peer leader benefit from both higher self-assessed learning gains and higher course grades than those students who do not, and this may be particularly true for STEM majors.

Student perceptions of positive learning gains and enjoyable interactions with peer leaders in PLTL sessions may have far-reaching impacts on a student's academic career, including the decision to declare or remain in STEM. A better understanding of student-peer leader relationships may lead to techniques for fostering stronger connections between students and their peer leaders. If the specific aspects of the student-instructor relationships that increase achievement and retention can be identified, this could have an impact on methods for recruitment and training of peer leaders, and potentially of instructors. And even small improvements in instructorstudent relationships can lead to an increase in student persistence and more STEM graduates (Christe, 2013; Vesilind, 2001; Vogt, 2008).

Given the importance of relatability and potential rolemodel status established in this study, future research should therefore seek to explore why students may find peer-leaders to be relatable or view them as role models. With a sufficiently large and diverse study population, this could be achieved via quantitative analyses investigating demographic and other characteristics that may impact the peer-leader/student relationship. Alternatively, qualitative investigations into how students may articulate what makes a peer-leader relatable or a potential role model, or not, would help elucidate the results reported here. This latter option is a strategy we are currently pursuing, particularly with regard to the similarities and competencies that Marx and Ko (2012) described as essential to role model status. Building our understanding of which qualities or characteristics of peer leaders make them particularly effective will inform our ongoing PLTL program, and potentially other programs in similar settings.

\section{Abbreviations \\ BIO 121: Introductory Biology Course; PLTL: Peer-Led Team Learning; SALG: Student Assessment of their Learning Gains; STEM: Science, Technology, Engineering and Mathematics}

\section{Acknowledgements}

The authors would like to sincerely thank Dr. Julia Snyder and Beverley Werner for their assistance in coordinating participants and technical skills in data organization. We also thank the Syracuse University Biology Department for its support throughout this research.

\section{Authors' contributions}

JRW serves as PI on the NSF grant funding the research and contributed to the project design and execution. CIW contributed to the design of all studies, playing the primary role in conceptualizing, acquiring and interpreting data. RDPD was responsible for data analysis and application and contributed to the design of the study and instrument selection. All authors read and approved the final manuscript.

\section{Funding}

The data presented herein and the development of this manuscript was funded by a grant from the National Science Foundation; (Award ID\# 1352740) EAGER: Enhancing Recruitment and Retention of Underrepresented Populations through PLTL (http://www.nsf.gov/awardsearch/ showAward?AWD_ID=1352740). Any opinions, findings, and conclusions or recommendations expressed in this material are those of the authors and do not necessarily reflect the views of the National Science Foundation. The funders had no role in study design, data collection and analysis, decision to publish, or preparation of the manuscript.

\section{Availability of data and materials}

The datasets used and/or analysed during the current study are available from the corresponding author on reasonable request.

\section{Ethics approval and consent to participate}

Student and peer-leader participants in this study consented to research and were recruited according to an Institutional Review Board approved protocol (14-313).

\section{Competing interests}

The authors declare that they have no competing interests.

Received: 12 September 2019 Accepted: 18 February 2020

Published online: 25 February 2020

\section{References}

Braxton, J. M., Milem, J. F., \& Sullivan, A. S. (2000). The influence of active learning on the college student departure process: Toward a revision of Tinto's theory. The Journal of Higher Education, 71(5), 569-590.

Brown, J. D., Novick, N. J., Lord, K. A., \& Richards, J. M. (1992). When Gulliver travels: Social context, psychological closeness, and self-appraisals. Journal of Personality and Social Psychology, 62(5), 717-727. https://doi.org/10.1037/ 0022-3514.62.5.717

Cassidy, S., \& Eachus, P. (2000). Learning style, academic belief systems, self-report student proficiency and academic achievement in higher education. Educational Psychology, 20(3), 307-322.

Chen, X. (2013). STEM attrition: College Students' paths into and out of STEM fields. Statistical analysis report. NCES 2014-001. Washington, DC: National Center for Education Statistics.

Christe, B. (2013). The importance of faculty-student connections in STEM disciplines: A literature review. Journal of STEM Education: Innovations and Research, 14(3), 22.

Drury, B. J., Siy, J. O., \& Cheryan, S. (2011). When do female role models benefit women? The importance of differentiating recruitment from retention in STEM. Psychological Inquiry, 22(4), 265-269.

Eberlein, T., Kampmeier, J., Minderhout, V., Moog, R. S., Platt, T., Varma-Nelson, P., \& White, H. B. (2008). Pedagogies of engagement in science: A comparison of PBL, POGIL, and PLTL. Biochemistry and Molecular Biology Education, 36(4), 262-273. https://doi.org/10.1002/bmb.20204.

Finn, K., \& Campisi, J. (2015). Implementing and evaluating a peer-led team learning approach in undergraduate anatomy and physiology. Journal of College Science Teaching, 44(6), 38-43.

Gosser, D., Cracolice, M., Kampmeier, J., Roth, V., Strozak, V., \& Varma-Nelson, P. (2001). Peer- led team learning: A guidebook. Upper Saddle River: Prentice Hall.

Gosser, D., Roth, V., Gafney, L., Kampmeier, J., Strozak, V., Varma-Nelson, P., Weiner, M. (1996). Chemical Educator, 1(1), 1-17.

Gosser Jr., D. K., \& Roth, V. (1998). The workshop chemistry project: Peer-led team learning. Journal of Chemical Education, 75, 185-187.

Johnson, E., Robbins, B., \& Loui, M. (2015). What do students experience as peer leaders of learning teams? Advances in Engineering Education, 4(4) Retrieved from https://publish.illinois.edu/loui/publications/.

Lau, L. K. (2003). Institutional factors affecting student retention. Education, 124(1), $126-136$

Lockwood, P., \& Kunda, Z. (1997). Superstars and me: Predicting the impact of role models on the self. Journal of Personality and Social Psychology, 73(1), 91-103. 
Marra, R. M., Rodgers, K. A., Shen, D., \& Bogue, B. (2012). Leaving engineering: A multi-year single institution study. Journal of Engineering Education, 101(1), 627. https://doi.org/10.1002/j.2168-9830.2012.tb00039.x.

Marx, D. M., \& Ko, S. J. (2012). Superstars "like" me: The effect of role mode similarity on performance under threat. European Journal of Social Psychology, 42(7), 807.

Micari, M., \& Pazos, P. (2012). Connecting to the professor: Impact of the studentfaculty relationship in a highly challenging course. College Teaching, 60(2), 41-47. https://doi.org/10.1080/87567555.2011.627576.

Multon, K. D., Brown, S. D., \& Lent, R. W. (1991). Relation of self-efficacy beliefs to academic outcomes: A meta-analytic investigation. Journal of Counseling Psychology, 38(1), 30-38.

National Science Board (2016). Science and engineering indicators 2016. Arlington: National Science Foundation (NSB-2016-1)

National Science Board (2018). Science and Engineering Indicators 2018. NSB-20181. Alexandria: National Science Foundation Available at https://www.nsf.gov/ statistics/indicators/.

Pascarella, E. T. (2006). How college affects students: Ten directions for future research. Journal of College Student Development, 47(5), 508-520. https://doi. org/10.1353/csd.2006.0060.

Peteroy-Kelly, M. A. (2009). A discussion group program enhances the conceptual reasoning skills of students enrolled in a large lecture-format introductory biology course. Journal of Microbiology \& Biology Education, 8(1), 13-21.

Prince, M. (2004). Does active learning work? A review of the research. Journal of Engineering Education, 93(3), 223-231. https://doi.org/10.1002/j.2168-9830. 2004.tb00809.x

Quitadamo, I. J., Brahler, C. J., \& Crouch, G. J. (2009). Peer-led team learning: A prospective method for increasing critical thinking in undergraduate science courses. Science Educator, 18(1), 29.

Scholl, K., \& Olsen, H. M. (2014). Measuring student learning outcomes using the SALG instrument. Schole, 29(1), 37-50.

Seymour, E., \& Hewitt, N. M. (1997). Talking about leaving: Why undergraduates leave the sciences. Boulder: Westview Press.

Seymour, E., Wiese, D., Hunter, A., \& Daffinrud, S. M. (2000). Creating a better mousetrap: On- line student assessment of their learning gains. San Francisco: Paper presentation at the National Meeting of the American Chemical Society.

Snyder, J. J., Carter, B. E., \& Wiles, J. R. (2015). Implementation of the peer-led team learning instructional model as a stop-gap measure improves achievement among students opting out of laboratory. CBE Life Sciences Education, 14(1), ar2. https://doi.org/10.1187/cbe.13-08-0168.

Snyder, J. J., Sloane, J. D., Dunk, R. D. P., \& Wiles, J. R. (2016). Peer-led team learning helps minority students succeed. PLoS Biology, 14(3), e1002398.

Snyder, J. J., \& Wiles, J. R. (2015). Peer-led team learning in introductory biology: Effects on peer leader critical thinking skills. PLoS One, 10(1), e0115084. https://doi.org/10.1371/journal.pone.0115084.

Stewart-Gardiner, C. (2010). Using peer led team learning to assist in retention in computer science classes. Journal of Computing Sciences in Colleges, 25, 164-171.

The White House (2018). Charting a course for success: America's strategy for STEM education https://www.whitehouse.gov/wp-content/uploads/2018/12/STEMEducation-Strategic-Plan-2018.pdf. Accessed 15 Jan 2019.

Tien, L. T., Roth, V., \& Kampmeier, J. A. (2004). A course to prepare peer leaders to implement a student-assisted learning method. Journal of Chemical Education, 81(9), 1313

Vesilind, P. A. (2001). Mentoring engineering students: Turning pebbles into diamonds. Journal of Engineering Education, 90(3), 407-411.

Vogt, C. M. (2008). Faculty as a critical juncture in student retention and performance in engineering programs. Journal of Engineering Education, 97(1), 27-36.

White, P., Rowland, A., \& Pesis-Katz, I. (2012). Peer-led team learning model in a graduate- level nursing course. Journal of Nursing Education, 51, 471-475.

Wilson, S. B., \& Varma-Nelson, P. (2016). Small groups, significant impact: A review of peer-led team learning research with implications for STEM education researchers and faculty. Journal of Chemical Education, 93(10), 1686.

Woodward, A., Gosser, D. K., \& Weiner, M. (1993). Problem solving workshops in general chemistry. Journal of Chemical Education, 70(8), 651-652.

Zerger, S., Clark-Unite, C., \& Smith, L. (2006). How supplemental instruction benefits faculty, administration, and institutions. New Directions for Teaching and Learning, 2006(106), 63-72. https://doi.org/10.1002/tl.234.

\section{Publisher's Note}

Springer Nature remains neutral with regard to jurisdictional claims in published maps and institutional affiliations.

\section{Submit your manuscript to a SpringerOpen ${ }^{\oplus}$ journal and benefit from:}

- Convenient online submission

- Rigorous peer review

- Open access: articles freely available online

- High visibility within the field

- Retaining the copyright to your article

Submit your next manuscript at $\boldsymbol{\nabla}$ springeropen.com 